\title{
CPR-associated right ventricular rupture in the setting of pulmonary embolism
}

\author{
Tyler B. M. Hickey, MD, PhD**; Ginjeet Gina K. Gill, MD ${ }^{\dagger \S}$; Michael A. Seidman, MD, PhD"; \\ Douglas L. Webber, MD**
}

\section{ABSTRACT}

Cardiopulmonary resuscitation (CPR) is an inherently traumatic procedure. Successful resuscitations are often complicated by iatrogenic injuries to structures of the neck, thorax, or abdomen. Rib and sternal fractures are the most frequently induced injuries. However, rare and life-threatening trauma to vital organs such as the heart may also occur during CPR. We describe a novel case of CPR-associated right ventricular rupture in a woman with acute-on-chronic pulmonary embolism and no known pre-existing cardiac disease. We propose that chest compressions in the setting of elevated right ventricular pressure resulted in cardiac rupture, in this case.

\section{RÉSUMÉ}

La réanimation cardiorespiratoire (RCR) est en ellemême une manœuvre traumatique. Les réanimations couronnées de succès se compliquent souvent de lésions iatrogènes aux structures du cou, du thorax ou de l'abdomen. Les fractures de côtes ou du sternum sont les lésions les plus fréquentes attribuables à la RCR. Toutefois, il peut arriver que des traumas extrêmement graves soient causés à des organes vitaux comme le cœur, mais le phénomène est rare. Sera exposé ici un nouveau cas de rupture du ventricule droit, associée à la RCR chez une femme ayant subi une embolie pulmonaire aiguë accompagnée de signes chroniques, mais ne souffrant pas d'une maladie cardiaque préexistante connue. Aussi sommes-nous d'avis que les compressions thoraciques effectuées dans le contexte d'une pression ventriculaire droite élevée se sont soldées par la rupture de la structure cardiaque.

Keywords: autopsy, resuscitation, cardiac injury, iatrogenic, pulmonary embolism

\section{CASE REPORT}

A 79-year-old woman with osteoporosis, dyslipidemia, and 1 year of unexplained weight loss (less than $30 \mathrm{lb}$ ) was on her way to see her family physician. She had booked the appointment because she had been feeling generally unwell and fatigued for several weeks-her condition worsening in recent days. She collapsed in her residential driveway, and paramedics attended to her within 10 minutes. At the scene, she was pulseless with agonaltype respirations, and the paramedics initiated CPR. On arrival at the local emergency department, the patient had a Glasgow Coma Scale of 3 and vital signs were absent. In the hospital, the patient received continued standard resuscitative efforts, including chest compressions, four external cardiac defibrillation attempts, oxygen delivery via bag-valve-mask and boluses of epinephrine, calcium, and bicarbonate. Chest compressions resulted in rib fractures and an unusual swelling of the right neck. The patient never achieved return of spontaneous circulation, and the health care providers ceased resuscitation efforts after 25 minutes of standard total CPR protocol.

A postmortem examination was requested to determine the cause of death. On opening the thorax, extensive blood was present throughout the soft tissues

From the *Departments of Pathology and Laboratory Medicine; tEmergency Medicine, Vancouver General Hospital, Vancouver, BC; $\S$ Departments of Emergency Medicine; $¥$ Pathology and Laboratory Medicine, University of British Columbia, Vancouver, BC; and $\llbracket$ Department of Pathology, St. Paul's Hospital, Vancouver, BC.

Correspondence to: Dr. Tyler B. M. Hickey, Department of Anatomical Pathology, Vancouver General Hospital, 899 W 12th Avenue, Vancouver, BC, Canada V5Z 1M9; Email: thickey@alumni.ubc.ca 
of the right anterior thorax and neck (Figure 1). Several right anterior rib fractures were apparent, and the right hemithorax contained $1300 \mathrm{~mL}$ of sanguineous fluid. Mediastinal examination revealed a $1-\mathrm{cm}$ tear of the anterior pericardium.

Additionally, the heart was remarkable for a $2-\mathrm{cm}$ transmural tear of the anterior right ventricle (Figure 2). No evidence of predisposing disease contributing to cardiac rupture was evident grossly (e.g., dilated cardiomyopathy, ventricular hypertrophy) or microscopically (e.g., prior myocardial infarction, myocarditis), and no evidence of antemortem tissue damage was evident, suggesting a traumatic rupture during resuscitation. Examination of the lungs revealed extensive thromboemboli in both large and small

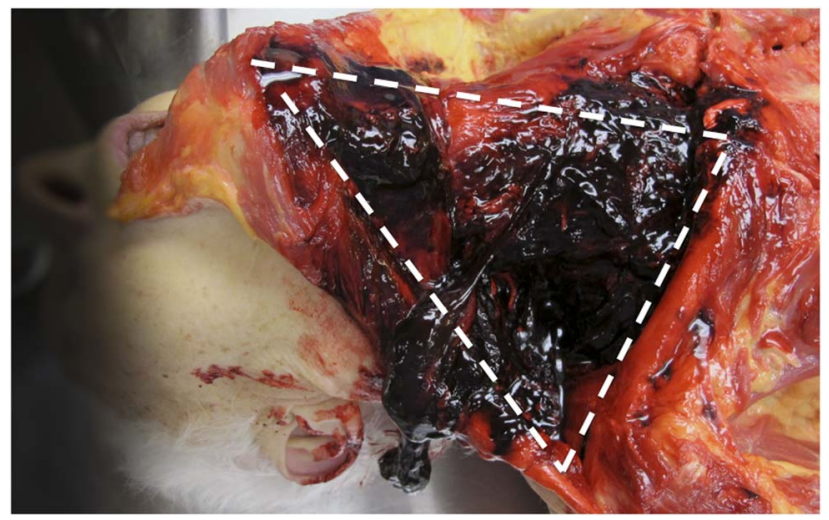

Figure 1. Extensive hemorrhage was observed within the tissues of the right neck (white triangle), mediastinum, and thorax. pulmonary vessels (Figure 3). Histologically, these showed both acute and chronic features, including varying degrees of organization, granulation, fibrosis, and recanalization. The pulmonary vessels did not show evidence of arterial atherosclerosis or small vessel muscular hypertrophy, as can be seen in chronic pulmonary hypertension. No putative source of thrombus was identified on examination of the deep veins of the legs.

In summary, the patient died from diffuse pulmonary emboli with traumatic rupture of the right ventricle secondary to chest compressions during CPR.

\section{DISCUSSION}

Injuries secondary to the trauma of CPR-associated chest compressions are common. Estimates of the incidence of some type of resuscitation injury ranges from $21 \%-65 \%,{ }^{1}$ and up to $97.4 \% .^{2}$ Although these injuries infrequently have a significant effect on the patient's outcome, ${ }^{3}$ clinicians should be mindful that anterior-posterior chest radiographs underestimate true fracture frequency. ${ }^{2}$ Hashimoto et al. ${ }^{1}$ reported that CPR results in an average of 7.1 broken ribs, with ribs 3-5 being the most frequently involved. Rib injuries occur with greater frequency in women and with increased age. ${ }^{3}$ Other CPR-associated injuries that occur with notable frequency ( $>20 \%$ of autopsy cases) include chest abrasion/contusion, defibrillator burns, sternal fractures, upper airway injuries, and pulmonary edema. ${ }^{4}$

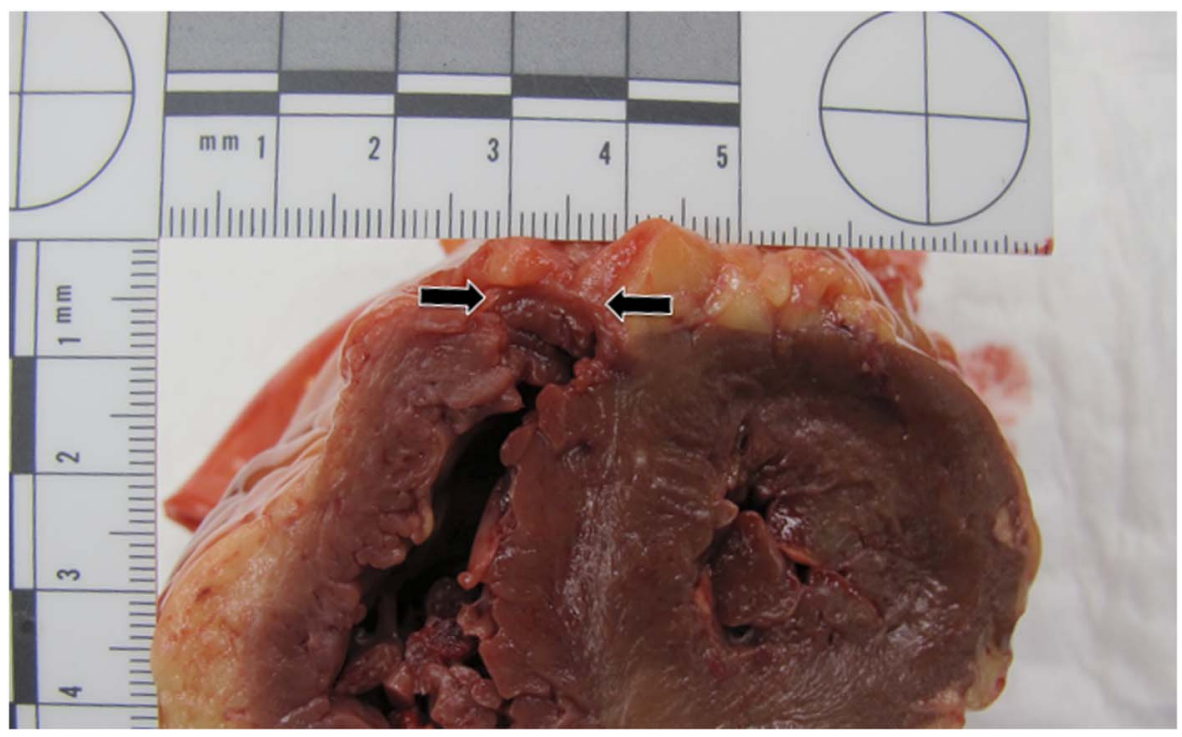

Figure 2. Presence of a transmural myocardial tear of the anterior right ventricle (located between black arrows). 


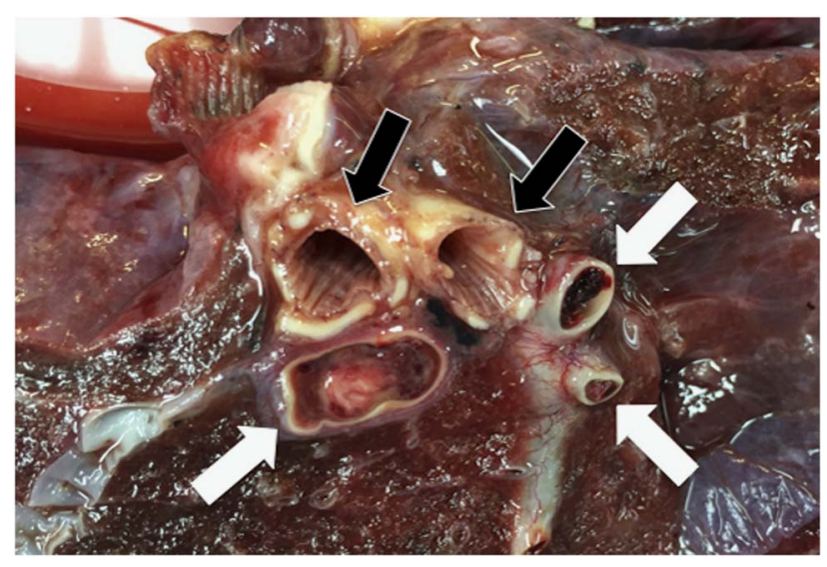

Figure 3. Occlusive thrombi were present within the large pulmonary arteries (white arrows). The large airways (black arrows) were unremarkable.

It is recognized that different methods of CPR result in different risks of thoracic wall trauma. Miller et al. ${ }^{5}$ compared standard CPR methodology (chest compressions using the hands only) with CPR, using active compression devices (ACDs) employing either suction cup, automated piston, or load-distributing band technologies. Their findings showed that sternal and rib fracture rates, respectively, were $8.5 \%$ and $25.9 \%$ in manual compression, $80.6 \%$ and $47.2 \%$ for suction cup ACD, and $16.9 \%$ and $25.4 \%$ for piston ACD. Use of load-distributing band ACD resulted in sternal fractures in $13.5 \%$ of cases (rib fractures were not reported for load-distributing band ACD). Hence, standard CPR appears to be less traumatic to the chest wall than ACD technologies.

Less frequent injuries resulting from $\mathrm{CPR}$ include liver lacerations $(0.6 \%-2.1 \%)$, gastric rupture $(<1 \%)$ and splenic lesions $(<1 \%){ }^{3} \mathrm{~A}$ rare complication of CPR is trauma to the heart and associated structures (e.g., great vessels and pericardium). Krischer et al. $^{4}$ reviewed 700 autopsy cases involving CPR and found vena cava trauma in $0.9 \%$ of cases and myocardial contusion in $1.3 \%$ of cases. In only a single case $(0.1 \%$ overall $)$ was there incidence of myocardial laceration. Similarly, in a review of 2659 autopsy cases, only three incidences of right ventricular rupture secondary to CPR were identified. ${ }^{6}$ Last, two comprehensive meta-analyses of CPRassociated injuries found myocardial rupture in only 5 of $818(0.6 \%)^{5}$ and $<1 \%$ of cases. ${ }^{7}$

Resuscitation-associated myocardial injury has been observed in a number of clinical settings, including cases of acute myocardial infarction, ${ }^{8}$ broken ribs, ${ }^{6,9}$ multiple large pulmonary emboli, ${ }^{10}$ and recent lung and pericardial surgery. ${ }^{11}$ Regardless of the mechanism of injury, myocardial injury carries a significant likelihood of mortality given the rapid progression to fatal exsanguination, ${ }^{12}$ but early recognition of the injury with prompt repair offers a chance of survival. ${ }^{8,12}$

In our case, similar to the description by Baldwin and Edwards, ${ }^{10}$ pulmonary emboli would have created an elevated right ventricular pressure, which is postulated to increase the likelihood of rupture. Additionally, although the fractured ribs were not adjacent to the heart at the time of postmortem examination, given the concurrent pericardial tear, it is possible that the ribs were displaced during chest compressions, contributing to cardiac rupture.

In summary, acute care clinicians should keep in mind that standard CPR is a traumatic intervention, and all successful resuscitations should be followed by a thorough evaluation for post-CPR injuries that may require treatment. Rib fractures are the most common injury, and women of increased age, especially with osteopenia/osteoporosis, are in the highest risk demographic. ${ }^{3}$ Although uncommon, injuries to the respiratory tract, gastroesophageal tract, upper abdominal organs, and cardiovascular system can all result from $\mathrm{CPR}$ and may present life-threatening injury in the post-resuscitation period. An assessment for iatrogenic myocardial injury in patients receiving CPR for diffuse pulmonary emboli should be considered.

Competing interests: None declared.

\section{REFERENCES}

1. Hashimoto Y, Moriya F, Furumiya J. Forensic aspects of complications resulting from cardiopulmonary resuscitation. Leg Med 2007;9(2):94-9.

2. Lederer W, Mair D, Rabl W, et al. Frequency of rib and sternum fractures associated with out-of-hospital cardiopulmonary resuscitation is underestimated by conventional chest X-ray. Resuscitation 2004;60(2):157-62.

3. Buschmann C, Tsokos M. Frequent and rare complications of resuscitation attempts. Intensive Care Med 2009;35(3): 397-404.

4. Krischer J, Fine E, Davis J, et al. Complications of cardiac resuscitation. Chest 1987;92(2):287-91.

5. Miller A, Rosati S, Suffredini A, et al. A systematic review and pooled analysis of CPR-associated cardiovascular and thoracic injuries. Resuscitation 2014;85(6):724-31.

6. Bodily K, Fischer RP. Aortic rupture and right ventricular rupture induced by closed chest cardiac massage. Minnesota Med 1979;62(4):225-7. 
7. Hoke R, Chamberlain D. Skeletal chest injuries secondary to cardiopulmonary resuscitation. Resuscitation 2004;63(3):327-38.

8. Natsuaki M, Yamasaki A, Morishige $\mathrm{N}$, et al. Right ventricular rupture induced by cardiopulmonary resuscitation. $7 \mathrm{C}$ Cases 2010;1(1):e42-4.

9. Sokolove P, Willis-Shore J, Panacek E. Exsanguination due to right ventricular rupture during closed-chest cardiopulmonary resuscitation. 7 Emerg Med 2002;23(2):161-4.
10. Baldwin J, Edwards J. Rupture of right ventricle complicating closed chest cardiac massage. Circulation 1976;53(3):562-4.

11. Kempen P, Allgood R. Right ventricular rupture during closed-chest cardiopulmonary resuscitation after pneumonectomy after pericardiotomy: a case report. Crit Care Med 1999;27(7):1378-9.

12. Martin T, Flynn T, Rowlands B, et al. Blunt cardiac rupture. 7 Trauma 1984;24(4):287-90. 